\title{
How is an international public health threat advanced in Canada? The case of antimicrobial resistance
}

\author{
Tsegaye L ${ }^{1}$, Huston $\mathrm{P}^{2}$, Milliken $\mathrm{R}^{2}$, Hanniman $\mathrm{K}^{2}$, Nesbeth $\mathrm{C}^{2}$, Noad L
}

\section{Abstract}

On September 21, 2016, the United Nations General Assembly held a high-level meeting on antimicrobial resistance (AMR). Participating political leaders committed to coordinate action across the human and animal health, agriculture and environmental sectors and to work at national, regional and international levels with the public sector, private sector, civil society and all other relevant actors, including the public.

The objective of this article is to outline how the Public Health Agency of Canada (PHAC) has been working to address AMR in Canada. PHAC has used a One Health approach and has been working at the federal level with other government departments and nationally with the provinces, territories, professional organizations and other key players to address AMR. To date, the federal response has focused on surveillance, stewardship and innovation across multiple sectors, including human health, animal health, regulatory actions and research. PHAC is currently working with the provinces and territories as well as key experts in the field to develop a pan-Canadian AMR Framework and subsequent action plan that will outline best practices and approaches to AMR across human and animal health. The Framework will build on previous work done by PHAC and the federal/provincial/territorial Pan-Canadian Public Health Network Council and recognizes the research expertise in Canada, the need to ensure actions are based on evidence, and to combat AMR through infection prevention and control.

The three articles in this issue are examples of the foundational work that has been done federally by PHAC, in developing the Canadian AMR Surveillance System (CARSS), and nationally, through task groups of the Public Health Network Council, in identifying where to strengthen human surveillance of AMR and best practices for stewardship in the human health care system. While we remain in an early stage of national, coordinated AMR action, momentum is building to ensure Canada can respond to this global health threat with a One Health approach involving multiple sectors at local, national and international levels that are all well-aligned with the World Health Organization Global Action Plan.
Affiliations

${ }^{1}$ Schulich School of Family Medicine and Dentistry, University of Western Ontario, London, ON

${ }^{2}$ Infectious Disease Prevention and Control Branch, Public Health Agency of Canada, Ottawa ON

*Correspondence: lindsay.noad@ phac-aspc.gc.ca

Suggested citation: Tsegaye L, Huston P, Milliken R, Hanniman K, Nesbeth C, Noad L. How is an international public health threat advanced in Canada? The case of antimicrobial resistance. Can Comm Dis Rep 2016;42(11):223-6. https://doi.org/10.14745/ccdr.v42i11a01

\section{Introduction}

Antimicrobial resistance (AMR) has been identified as a fundamental threat to global health security as well as a threat to meeting and maintaining international development goals $(1,2)$. The World Health Organization's (WHO) 2014 report on the global surveillance of AMR highlighted the risk of entering a post antibiotic era where common infections could become life threatening due to the progressive loss of effective treatments (3). It has been estimated that by 2050 , annual deaths due to AMR could reach 10 million worldwide, overtaking deaths due to diabetes and cancer combined (4). What makes the situation especially difficult is that AMR is not just a human health threat, it is a complex issue that has animal, agricultural, environmental and economic implications.
In September 2016, a high-level meeting was held on AMR at the United Nations General Assembly (UNGA). This was only the fourth time that UNGA had discussed a health issue, which demonstrates both the international commitment and the grave threat posed by AMR. Heads of state committed to take a broad, coordinated approach to address AMR by developing national plans. They pledged to strengthen regulation of antimicrobials, improve knowledge and awareness and promote best practices-as well as to foster innovative approaches using alternatives to antimicrobials and new technologies for diagnosis and vaccines. "Antimicrobial resistance poses a fundamental threat to human health, development and security. The commitments made today must now be translated into swift, effective, lifesaving actions across the human, animal and 
environmental health sectors. We are running out of time," said Dr. Margaret Chan, Director-General of WHO (5).

So how is a complex global public health threat addressed nationally? In Canada, we have taken a One Health approach to AMR that recognizes that the health of humans is connected to the health of animals and the environment (6). The objective of this article is to provide an update on how the Public Health Agency of Canada (PHAC) has been working at the international, federal and national (federal/provincial/territorial) levels to build the foundation for a coordinated, multi-sector or multi-sectoral response in Canada that is well-aligned with international efforts. This editorial will highlight some of the work that has been done in the health sector and describe a new multi-sectoral approach that is now underway.

\section{International coordination}

As the Government of Canada's focal point for international work on AMR, PHAC has been actively engaged in a number of international policy and expert forums on all aspects of AMR. These forums have included the WHO, the Food and Agricultural Organization (FAO), the World Organization for Animal Health (OIE), the G7, the G20 and the Global Health Security Agenda (GHSA) who have all identified AMR as a key area of concern requiring coordinated action and capacity-building. Canada is actively supporting these efforts. One of Canada's key commitments to date has been the endorsement of the WHO Global Action Plan (GAP) on AMR (7), which includes the development of a multi-sectoral national action plan. At the September 2016 United Nations General Assembly highlevel meeting on AMR, Canada reaffirmed its commitment to develop a national action plan on AMR and pledged support for the political declaration on AMR (8). This declaration identified support for activities focused on stewardship, surveillance, regulation, research and innovation, and capacity-building at the regional, national and global levels. PHAC is committed to sharing intelligence and outcomes of international meetings and ensuring that Canadian initiatives and activities align with the WHO Global Action Plan.

\section{Federal action}

\section{The Federal Framework and Action Plan}

Given the complex nature of AMR, responsibility for action crosses the mandates of a number of federal departments and agencies. A coordinated federal approach is essential to effectively launch a pan-Canadian approach to AMR and international AMR initiatives. PHAC led the development of Antimicrobial Resistance and Use in Canada: A Federal Framework for Action (9). The federal Framework set out three pillars to guide federal actions:

1. Establish and strengthen surveillance systems.

2. Strengthen the promotion of the appropriate use of antimicrobials (stewardship).

3. Promote innovation.

The Framework was followed by the Federal Action Plan on Antimicrobial Resistance and Use in Canada, which identified concrete actions to be undertaken by the Government of
Canada to achieve the Framework objectives (10). Federal departments undertaking work under the Action Plan include Health (Public Health Agency of Canada, Health Canada, the Canadian Institutes of Health Research and the Canadian Food Inspection Agency); Agriculture and Agri-food Canada; the National Research Council Canada; and Innovation, Science and Economic Development Canada. Discussions continue across federal departments regarding how to further advance Canada's response to AMR and have expanded to include Environment and Climate Change Canada, as well as Global Affairs Canada (Figure 1).

\section{Figure 1: Federal departments taking action on AMR through the Federal Action Plan}

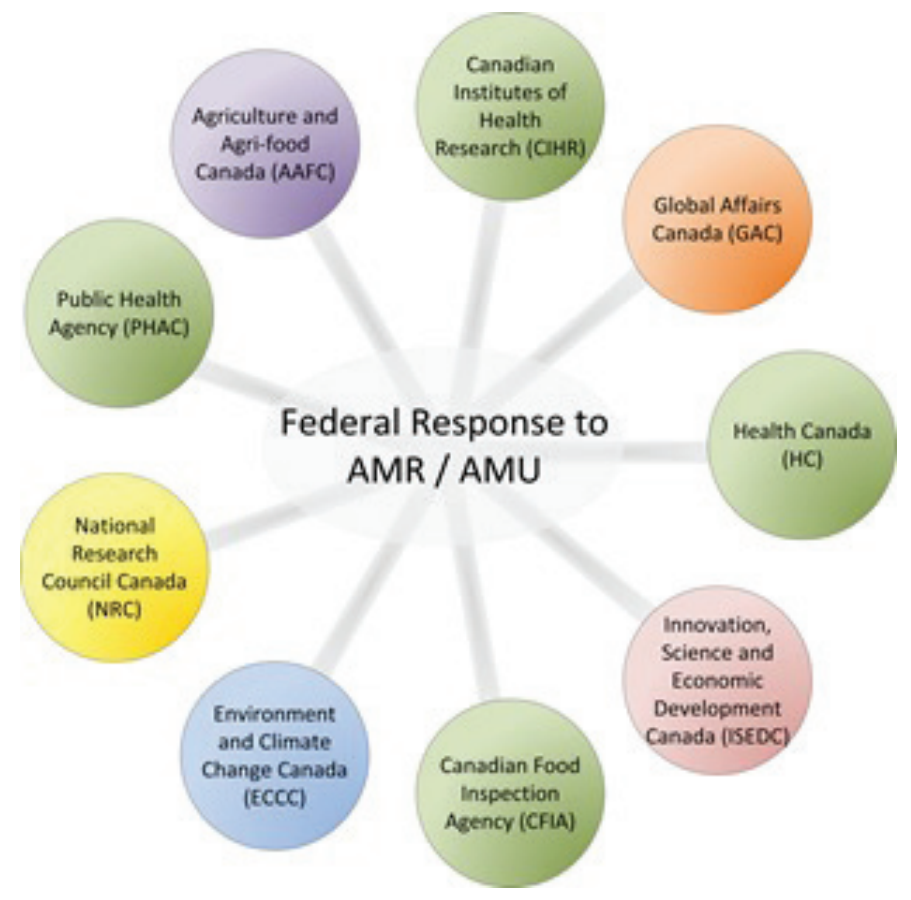

The Government of Canada has been working on its commitments in the Federal Action Plan. Here are a few examples of how it has been working on each of the pillars with a special focus on the work of the Agency.

\section{The Canadian AMR Surveillance System (CARSS)}

The Canadian Antimicrobial Resistance Surveillance System (CARSS) was launched in 2014 to strengthen surveillance coordination. CARSS is based at PHAC and supported by Health Canada, the CFIA and AAFC. CARSS integrates data about antimicrobial use (AMU) and AMR from nine surveillance systems.

This issue of the Canada Communicable Disease Report includes a summary of the second CARSS report (11). The report identifies AMU and AMR trends in both food production animals (e.g. chickens, cows, pigs) and humans, and tracks priority organisms for surveillance. The report highlights that while AMR rates for some organisms have stayed the same or declined, methicillin-resistant Staphylococcus aureus (MRSA) rates are higher than in the early-mid 2000s. Of particular concern are the rising rates of drug-resistant Neisseria gonorrhoeae in the 
community. Athough antibiotic use in Canadian hospitals has remained relatively stable, there is a trend towards increased use of parenteral (intravenous) antibiotics in the community. Additionally, antimicrobials important to human medicine were distributed for use in food production animals. In 2014 approximately $82 \%$ of antibiotics in Canada were for use in food production animals; only $18 \%$ were for human use (11).

\section{Stewardship, research and innovation}

The Government of Canada is addressing AMR in the other two pillars as well: stewardship and research and innovation. With respect to stewardship, there has been work in the animal health area to moderate antibiotic use, including strengthening regulations and policy for veterinary medicines and medicated feeds. Health Canada has proposed amendments to the Food and Drug Regulations to help address the issue of AMR in the veterinary drugs context, work that is complimentary to policy initiatives also currently underway, including the removal of growth promotion claims of medically-important antimicrobials and their change of status from over-the-counter to prescription. PHAC has supported and promoted a number of local stewardship initiatives (12) and, as described below, has worked with provinces and territories to identify best practices in antimicrobial stewardship.

Surveillance findings have informed stewardship, research and innovation. Programs have covered a wide range of activities, including the development of novel antimicrobials, alternatives to antibiotics, transmission dynamics and diagnostics. In addition to its investigator-initiated research funding, CIHR has supported a number of AMR-related programs since its inception in 2000 (13), and current targetted funding is focused on point-of-care diagnostics for priority pathogens (14) and various topics (e.g, transmission dynamics, development of new drugs) through the European Union Joint Programming Initiative on Antimicrobial Resistance (JPIAMR), an international collaboration of 22 member states (15). Along with PHAC and the NRC, CIHR also co-led a federal working group of 13 organizations focused on identifying priorities for vaccine research, innovation and development, which has the potential to lead to a decreased rate of new antimicrobial resistant infections. The Genomics Research and Development Initiative is another example of innovation and federal multi-disciplinary collaboration. This multi-year program enables federal science departments and agencies to address important biological issues, including how AMR develops and spreads.

\section{National health initiatives}

Efforts are underway in human health and animal health sectors. As an example, in the human health sector, PHAC has been working at a national level with the Public Health Network (PHN) Council. The PHN Council is composed of senior health officials from all the provinces and territories plus the Chief Public Health Officer of Canada (16). The Council accomplishes its developmental work through steering committees and task groups.

To identify some of the key human health issues in AMR, the PHN Council's Communicable and Infectious Disease Steering Committee (CIDSC) set up two time limited task groups that included experts and other key stakeholders from across the country: the AMU Surveillance Task Group and the AMR Stewardship Task Group. Each task group developed a report for CIDSC to present to the PHN Council.

\section{Strengthening AMR surveillance}

The CIDSC AMR Surveillance Task Group was asked to identify the data requirements for first priority organisms for AMR surveillance in Canada, to determine whether they are being met or not, to assess the feasibility of meeting unmet data requirements and to make recommendations regarding surveillance gaps (17). For just over half of the high priority data requirements, the Task Group found the existing surveillance systems met the required needs. It found that a number of data requirements were not being met and the feasibility of gathering this data was variable. The Task Group recommended that the top priority site of infection for AMR surveillance was the bloodstream due to the high associated morbidity and mortality of bloodstream infections. Another recommendation was to collect susceptibility data on $\mathrm{N}$. gonorrhoeae in the community given the rise in resistance and current gaps.

\section{Best practices in antimicrobial stewardship}

The CIDSC Stewardship Task Group conducted a scan of best practices in stewardship and developed recommendations to promote stewardship (18). Recommendations include the promotion of stewardship across jurisdictions by instituting a national infrastructure; advancing best practices for education and awareness; developing evidence-based audit and feedback tools; collecting, sharing and mobilizing evidence about prescribing professionals to implement specific targeted interventions; and changing healthcare practitioners' practice regulations.

\section{Next steps}

\section{Developing a pan-Canadian framework}

In order to deliver a multi-sectoral national plan, as per Canada's international commitments, PHAC has been working with the human and animal health and agriculture governance systems, and has initiated the creation of a new federal/provincial/ territorial AMR Governance Structure, reflective of an integrated One Health approach needed for coordinated, comprehensive multi-sectoral actions for a pan-Canadian approach.

This new governance structure is composed of federal/provincial/ territorial government officials representing public health, healthcare, animal health and the agri-food sector from all levels of government as well as key stakeholders from academia and industry. The structure is being used to facilitate the development of the pan-Canadian Framework on AMR.

\section{Conclusion}

How is an international public health threat addressed in Canada? The case of AMR goes beyond human health and requires a One Health approach with multi-sector action at local, 
regional, national and international levels. The WHO Global Action Plan on AMR and the recent commitment by Heads of State worldwide to address the root causes of AMR will enable a high level of collaboration and coordination. Although a lot of foundational work has been completed in Canada, there is still much to be done. As Canada moves forward with its pan-Canadian Framework and action plan, ongoing engagement with domestic and international partners across all sectors will be key to ensuring alignment and protecting the health and welfare of not just Canadians, but the global community.

\section{Acknowledgements}

Many thanks to all the front line clinicians, veterinarians, health care administrators, academics, government officials, regulators, researchers, politicians and more who have been fighting the battle against AMR on multiple fronts.

\section{Conflict of interest}

None. Dr. Patricia Huston is the Editor-in-Chief of the Canada Communicable Disease Report and recused herself from taking editorial decisions on this manuscript. Editorial decisions were made by the two the Guest Editors, Jacqueline Arthur and Dr. Kanchana Amaratunga.

\section{References}

1. United Nations [Internet]. The millennium development goals report 2015. New York, NY: United Nations; 2015. Available from: http://www.undp.org/content/dam/undp/library/MDG/ english/UNDP_MDG_Report_2015.pdf.

2. United Nations [Internet]. Transforming our world.

The 2030 agenda for sustainable development. New York, NY: United Nations; 2015. Available from: https://sustainabledevelopment.un.org/content/ documents/21252030\%20Agenda\%20for\%20Sustainable\%20 Development\%20web.pdf.

3. World Health Organization (WHO) [Internet]. Antimicrobial resistance: Global report on surveillance, 2014. Geneva: WHO; 2014. Available from: http://apps.who.int/iris/ bitstream/10665/112642/1/9789241564748_eng.pdf?ua=1.

4. O'Neill J [Internet]. The review on antimicrobial resistance. London, UK: Her Majesty's Government; 2016. Available from: https://amr-review.org/.

5. Press release: High-level meeting on antimicrobial resistance [Internet]. Sep 21 2016. Available from: http://www. un.org/pga/71/2016/09/21/press-release-hl-meeting-onantimicrobial-resistance/.

6. Public Health Agency of Canada [Internet]. One health. Ottawa, ON: PHAC; 2013. [updated 2013 Mar 28; cited 2016 Oct 11]. Available from: http://www.phac-aspc.gc.ca/owohumus/index-eng.php.
7. World Health Organization (WHO) [Internet]. International health regulations. Geneva: WHO; 2005. Available from: www. who.int/ihr/publications/9789241596664/en.

8. United Nations General Assembly [Internet]. Draft political declaration of the high-level meeting of the General Assembly on antimicrobial resistance. New York, NY: United Nations; 2016. Available from: http://www.un.org/pga/71/wp-content/ uploads/sites/40/2016/09/DGACM_GAEAD_ESCAB-AMRDraft-Political-Declaration-1616108E.pdf.

9. Public Health Agency of Canada [Internet]. Antimicrobial resistance and use in Canada: A federal framework for action. Ottawa: Government of Canada; 2014. Available from: http:// healthycanadians.gc.ca/alt/pdf/drugs-products-medicamentsproduits/buying-using-achat-utilisation/antibiotic-resistanceantibiotique/antimicrobial-framework-cadre-antimicrobienseng.pdf.

10. Public Health Agency of Canada [Internet]. Federal action plan on antimicrobial resistance and use in Canada: Building on the federal framework for action. Ottawa: PHAC; 2015. Available from: http://healthycanadians.gc.ca/alt/pdf/ publications/drugs-products-medicaments-produits/antibioticresistance-antibiotique/action-plan-daction-eng.pdf.

11. Public Health Agency of Canada [Internet]. Canadian Antimicrobial Resistance Surveillance System report 2016. Ottawa, ON: PHAC; 2016. Available from: http:// healthycanadians.gc.ca/publications/drugs-productsmedicaments-produits/antibiotic-resistance-antibiotique/alt/ pub-eng.pdf

12. Taylor G. The importance of stewardship. Can Comm Dis Rep. 2015;41(S-4):3-5. Available from: http://www.phac-aspc.gc.ca/ publicat/ccdr-rmtc/15vol41/dr-rm41s-4/editorial-eng.php/.

13. Canadian Institutes of Health Research [Internet]. About ClHR's antimicrobial resistance initiatives. Ottawa, ON: Government of Canada; 2015. [updated 2015 Apr 13; cited 2016 Oct 11]. Available from: http://www.cihr-irsc. gc.ca/e/40485.html.

14. ResearchNet [Internet]. Funding opportunity details: Antimicrobial resistance. [updated 2016 Aug 16; cited 2016 Oct 11]. Available from: https://www.researchnetrecherchenet.ca/rnr16/vwOpprtntyDtls.do?prog=2441\&view= currentOpps\&type $=$ EXACT\&resultCount $=25 \&$ sort $=$ program \& all=1\&masterList=true.

15. Joint Programming Initiative on Antimicrobial Resistance (JPIAMR) [Internet]. Home page. Stockholm, Sweden: JPIAMR; 2015. [updated 2015; cited 2016 Oct 11]. Available from: http://www.jpiamr.eu/

16. Pan-Canadian Public Health Network (PHN) [Internet]. Overview. Ottawa, ON: PHN; 2016. [updated 2016 Mar 21; cited 2016 Oct 11]. Available from: http://www.phn-rsp.ca/ index-eng.php.

17. Amaratunga $K$, Tarasuk J, Tsegaye L, Archibald CP and the 2015 Communicable and Infectious Disease Steering Committee (CIDSC) AMR Surveillance Task Group. Advancing surveillance of antimicrobial resistance: Summary of the 2015 CIDSC Report. Can Comm Dis Rep. 2016;42(11):232-7. Available from: http://webqa.phac-aspc.gc.ca/publicat/ccdrrmtc/16vol42/dr-rm42-11/ar-03-eng.php.

18. Khan F, Arthur J, Maidment L, Blue D on behalf of the 2015 CIDSC Task Group on AMU Stewardship. Advancing antimicrobial stewardship in Canada: Summary of the CIDSC Report. Can Comm Dis Rep. 2016;42(11):238-41. Available from: http://webqa.phac-aspc.gc.ca/publicat/ccdrrmtc/16vol42/dr-rm42-11/ar-04-eng.php. 